\title{
Socio-demographic characteristics and tobacco use among the adults in urban slums of Dhaka, Bangladesh
}

\author{
Nusrat Nausheen Khandker ${ }^{1}$, Tuhin Biswas ${ }^{2}$, Abdullah Nurus Salam Khan², Enamul Hasib ${ }^{1}$ and Lal B Rawal ${ }^{12^{*}}$
}

\begin{abstract}
Background: Use of tobacco has become one of the major causes of premature deaths in most developing countries, including Bangladesh. The poorest and most disadvantaged populations, such as those living in slums, are considered to be extremely vulnerable to non-communicable diseases and their risk factors, especially tobacco use. The objective of this study was to assess the current status of tobacco consumption among slum dwellers and its association with socio-demographic factors.
\end{abstract}

Methods: A cross-sectional study was conducted in three slums of Dhaka city. Information about tobacco use as well as socio-demographic characteristics was collected from adult slum dwellers via face to face interviews using WHO STEPS questionnaire.

Result: Overall proportion of smoking, smokeless tobacco consumption and dual use of tobacco was 35\% [95\% Cl: 31.6-39.8], 40.6\% [95\% Cl: 36.5-45.2] and 12\% [95\% Cl: 9.3-15.0] respectively. Elderly people (55-64 years) were more likely to smoke (OR: $2.34,95 \% \mathrm{Cl}: 1.21-4.49)$ than younger people (aged 25-34 years). On the other hand, those who had no schooling history (OR: 2.95, 95\% Cl: 1.66-5.25) were more likely to consume smokeless tobacco than those who had higher education (secondary or above). At the same time, manual workers were more likely to indulge in dual use of tobacco (OR: 5.17, 95\% Cl: 2.82-9.48) as compared to non-manual workers.

Conclusion: The urban slum population of Dhaka city has a high prevalence of tobacco use, which increases their likelihood of developing non-communicable diseases. Proper attention needs to be directed towards addressing the risk factors related to non-communicable diseases within this vulnerable population.

Keywords: Tobacco use, Urban slum, Dhaka, Bangladesh

\section{Background}

Tobacco use has been unanimously regarded as one of the leading preventable causes of death and disability worldwide [1]. About 6 million people die each year as a result of tobacco use [2]. According to the Global Burden of Disease report (2010), consumption of tobacco products leads to premature deaths as well as disability accounting for $6.9 \%$ of years of life lost and $5.5 \%$ of disability-adjusted life-years (DALYs) respectively [3]. Tobacco use has also been recognized as one of the four behavioural risk factors responsible for causing non-

\footnotetext{
* Correspondence: dr.lalrawal@gmail.com

${ }^{1}$ James P Grant School of Public Health, BRAC University, Dhaka, Bangladesh

${ }^{2}$ Health Systems and Population Studies Division, icddr, b Level 5, 68

Shaheed Tajuddin Ahmed Sharani, Mohakhali, Dhaka 1212, Bangladesh
}

communicable diseases (NCDs), especially the four major NCDs namely cardiovascular diseases, chronic respiratory diseases, type 2 diabetes mellitus and cancer [1]. The harms of tobacco use are not only limited to the user. Second-hand smoking (SHS) also has serious health consequences, and causes about 600,000 deaths worldwide [2].

It has been estimated that more than two-thirds of deaths due to tobacco consumption occur in the low and middle income countries [4]. The nations in South-East Asian Region (SEAR) have one of the highest burdens of tobacco-related morbidity and mortality. More than 1 million out of the 6 million tobacco-attributable deaths worldwide, occur in the SEAR countries [5]. Two vital issues that draw attention to the tobacco use pattern in the 
SEAR countries (especially India and Bangladesh) are the increased consumption of smokeless tobacco (SLT) and the use of bidis (hand-rolled cigarettes), which pose more of a threat to people's health because of the high content of nicotine and other harmful chemicals [5].

Like other developing countries, Bangladesh too faces a huge burden of tobacco consumption and its related illnesses. The Global Adult Tobacco Survey (GATS), 2009, estimates that $43.3 \%$ of Bangladeshis (aged 15 and above) use tobacco in some form or the other [6]. Data from the NCD risk factor survey in Bangladesh showed an overall tobacco use prevalence of $54 \%$ among adults over 25 years of age [7]. Studies have shown this high prevalence to be linked with a higher morbidity and mortality due to tobacco use. A proportional mortality study revealed that in 2010, smoking-attributable mortality in Bangladeshi men aged between 25 to 69 years was about 25\% [8]. Another study, published in 2013, echoes these findings and attributes $25 \%$ of the deaths in men and $7.6 \%$ of the deaths in females to smoking [9]. The same study also reports an increased risk of mortality from cancer and ischemic heart disease as well as an increase in all-cause mortality among men who smoked, as compared to their non-smoker counterparts [9].

Studies have suggested that the prevalence of tobacco use is high in poor people [10] and it has been found that people from households in the poorest quintiles in low and middle income countries such as Bangladesh, are twice more likely to smoke than the wealthier households [11]. In Bangladesh, the poorest people live in slums and account for about one-third of the urban population [12]. The urban slum dwellers are not only economically disadvantaged, but live in overcrowded settlements with low levels of sanitation and hygiene, open garbage disposal, lack of proper healthcare facilities and so on, which readily contribute to ill health and disease [12, 13]. These factors, along with changing behavioral norms related to NCD risk factors in developing countries [14], make the slum dwellers a high-risk population for tobacco use and development of NCDs. The International Tobacco Control (ITC) Bangladesh Survey revealed that the prevalence of tobacco use among slum-dwellers was much higher (78.8\%) as compared to the rest of the urban population [15]. Studies conducted in neighboring countries like India also proclaimed higher rates of tobacco usage within their slum population $[16,17]$

It can thus be estimated from national surveys and other studies conducted in similar contexts, that the slum population has a higher prevalence of tobacco use. However, there is a dearth of studies with special focus on disadvantaged populations such as the urban slum dwellers. Also, after the ITC Bangladesh Survey in 2010, there has been no routine surveillance on tobacco use.
Rapid urbanization resulting in an increased slum population over the past few years, coupled with changing norms due to globalization have had an impact on the lifestyles of the people living in these areas. This makes it even more crucial to obtain up-to-date information on this vulnerable population, which can aid in assessing the magnitude of NCD risk and related problems among the slum dwellers. This study aimed to bring out the current picture of tobacco use among the adults residing in the urban slums of Dhaka and to examine any association between tobacco use and the socio-demographic characteristics of the respondents.

\section{Methods}

\section{Study setting and population}

A cross-sectional study was carried out in three purposively selected urban slums of Dhaka, namely Korail slum in Gulshan, Bhashantek slum in Mirpur and Rayerbazar slum in Dhanmondi. The study population comprised of adult slum dwellers (aged 25 to 64 years) residing in those slums. This age group has been recommended by WHO as the target age group for the survey of NCD risk factors [18]. Persons living in the selected slums for at least 6 months were included in the study. This study was a part of a larger study which also collected data on other NCD risk factors including alcohol consumption, food and vegetable intake, anthropometric and blood pressure measurement using the WHO STEPS Questionnaire and are in process of being published elsewhere. In order to align with the aim of the larger study and collect as comprehensive data as possible, the critically ill or bed-ridden persons, pregnant women and physically or mentally challenged individuals who were unable to participate in the study were excluded.

\section{Sampling strategy}

Multi-stage cluster sampling was adopted, whereby households were selected as the sampling units. Using existing maps of the three slums, geographical clusters were identified based on road networks. The clusters were divided in such a manner that they were nearly equal on visual estimation. In order to obtain uniform samples from each slum, the total sample size (507, rounded off to 510 for the ease of calculations) was divided into three equal portions. From the clusters identified within one slum, two clusters were selected by simple random sampling (random number generation). Real time images of each cluster were obtained by using Google Earth and used as guides for sampling. Households were selected using systematic random sampling. Alternate households were approached and male and female respondents were also chosen from these households in an alternate manner. If there were more than one eligible member within a household, one respondent was 
selected randomly by lottery. Finally, 507 eligible participants completed the interview and physical measures were taken.

\section{Data collection process}

Data was collected via face-to face interviews, using a structured questionnaire. The questionnaire was adopted from the Step 1 of WHO STEPS Questionnaire [19]. The demographic information section and individual sections on tobacco use were adopted with minor contextual modifications. A validated Bengali version of the WHO STEPS Questionnaire was consulted for translation of the tool into Bengali [7].

The participants were mainly asked about their consumption of "smoked tobacco" and "smokeless tobacco". According to the NCD Global Monitoring Framework guidelines, "smoked tobacco products includes the consumption of cigarettes, bidis, cigars, cheroots, pipes, shisha (water pipes), fine-cut smoking articles (roll-your-own), krekets, and any other form of smoked tobacco"[20]. On the other hand, "smokeless tobacco includes moist snuff, plug, creamy snuff, dissolvables, dry snuff, gul, loose leaf, red tooth powder, snus, chimo, gutkha, khaini, gudakhu, zarda, quiwam, dohra, tuibur, nasway, naas/naswar, shammah, betel quid, toombak, pan (betel quid), iq'mik, mishri, tapkeer, tombol and any other tobacco product that is sniffed, held in the mouth, or chewed" [20].

The data were collected by trained interviewers, which included physicians and trained field research assistants with a health science background. Data collectors were exclusively trained on anthropometric measurements and physical examination. The English version of the questionnaire was prepared, which was then translated into Bangla version once we had expert review and comments/feedback from the subject experts. The Bangla version questionnaire was back translated into English once the pilot testing was completed to establish the reliability and validity of the translation. The final pilot tested Bangla version questionnaire was used for data collection.

\section{Ethics approval}

The ethics approval for conducting this study was obtained from the Ethical Review Committee of James $\mathrm{P}$ Grant School of Public Health, BRAC University, Bangladesh. During data collection, the research objectives and procedures were explained to the participants in Bengali. Due to the contextual setting where most of the participants were illiterate and because of the sensitive nature of requesting thumbprints or signatures, verbal informed consent was taken from the participants before the interviews. The consent script was read out clearly by the interviewer at the beginning of each interview and their consent to participate or not to participate in the study was sought.

\section{Data management and quality control}

Prior to the study, the questionnaire was pre-tested among slum adult populations residing in another slum area (Shattola slum in Mohakhali, Dhaka). Data collectors were trained extensively before going to the field. Demonstrations and mock-interviews were also carried out. Random checks of the interviews were performed to identify any non-response pattern or errors in data collection.

\section{Statistical analysis}

Data was analyzed using the statistical software, IBM SPSS Statistics (version 20). 507 samples were used for overall analysis. As per the WHO STEPS Surveillance Data Analysis guideline, records having missing data for the age variable were dropped [19]. Non-responses for particular sections were taken into account while analyzing those specific sections. Frequencies and descriptive statistics were obtained and reviewed. Some of the numeric data were categorized, e.g. age was categorized into 4 categories according to the WHO guidelines [21]. Bi-variate analysis was carried out by cross-tabulating the outcome variables against the socio-demographic variables. Binary logistic regression was conducted to examine the significant correlates of socio-demographic variables with tobacco consumption.

\section{Results}

The socio-demographic characteristics of all the respondents categorized by gender, are shown in Table 1 . The mean $( \pm$ SD) age of the participants was $37.9( \pm 11.2)$ years and majority $(44.6 \%)$ of them were within the $25-$ 34-year age group. Of participants, just above half (50.3\%) were males and about half of the respondents (51.5\%) had no formal education. Most of the respondents (about 70\%) were non-manual workers and majority of them were married (91.7\%).

The overall tobacco consumption (which includes both smoked and smokeless tobacco) among the adult slum population was $64 \%$. Consumption patterns under each of the following categories, smoking, smokeless tobacco consumption and dual use of tobacco were 35\% [95\% CI: 31.6-39.8], 40.6\% [95\% CI: 36.5-45.2] and 12\% [95\% CI: 9.3-15.0] respectively. The prevalence of tobacco smoking was much higher among the males than the females (Table 2). About 70.6\% [95\% CI: 65.1-76.08] of the male respondents smoked tobacco as opposed to only $0.4 \%$ [95\% CI: 0-1.19] of the females. However, consumption of smokeless tobacco (SLT) was more prevalent in females ( $48.8 \%$ vs. $32.6 \%)$. Also, among the males $23.5 \%$ indulged in dual use of tobacco, i.e. use of both smoked and smokeless tobacco.

Among those who used smoked tobacco products, majority $(89 \%)$ smoked manufactured cigarettes. The mean 
Table 1 Socio-demographic characteristics of the adults by gender

\begin{tabular}{|c|c|c|c|}
\hline Variables & $\begin{array}{l}\text { Total n (\%) } \\
n=507\end{array}$ & $\begin{array}{l}\text { Male } \mathrm{n}(\%) \\
n=255\end{array}$ & $\begin{array}{l}\text { Female } \mathrm{n}(\%) \\
n=252\end{array}$ \\
\hline \multicolumn{4}{|l|}{ Age Categories (in years) } \\
\hline Mean \pm SD & $37.9 \pm 11.2$ & $39.5 \pm 11.7$ & $36.3 \pm 10.4$ \\
\hline $25-34$ & $226(44.6 \%)$ & $107(42.0 \%)$ & $119(47.2 \%)$ \\
\hline $35-44$ & $138(27.2 \%)$ & $64(25.1 \%)$ & $74(29.4 \%)$ \\
\hline $45-54$ & $78(15.4 \%)$ & $41(16.1 \%)$ & $37(14.7 \%)$ \\
\hline $55-64$ & $65(12.8 \%)$ & $43(16.9 \%)$ & $22(8.7 \%)$ \\
\hline \multicolumn{4}{|l|}{ Highest Level of Education } \\
\hline No Formal Education & $261(51.5 \%)$ & $109(42.8 \%)$ & $152(60.3 \%)$ \\
\hline Below Primary Level & $86(17.0 \%)$ & $59(23.1 \%)$ & $27(10.7 \%)$ \\
\hline Primary Education completed & $62(12.2 \%)$ & $31(12.2 \%)$ & $31(12.3 \%)$ \\
\hline Secondary Education and above & $98(19.3 \%)$ & $56(21.9 \%)$ & $42(16.7 \%)$ \\
\hline \multicolumn{4}{|l|}{ Occupation } \\
\hline Non-manual & $354(69.8 \%)$ & $117(45.9 \%)$ & $237(94.0 \%)$ \\
\hline Manual & $153(30.2 \%)$ & $138(54.1 \%)$ & $15(6.0 \%)$ \\
\hline \multicolumn{4}{|l|}{ Marital Status } \\
\hline Never Married & $26(5.1 \%)$ & $22(8.6 \%)$ & $4(1.6 \%)$ \\
\hline Currently Married & 465 (91.7\%) & $232(91.0 \%)$ & $233(92.4 \%)$ \\
\hline Widowed/Divorced/Separated & $16(3.2 \%)$ & $1(0.4 \%)$ & $15(6.0 \%)$ \\
\hline \multicolumn{4}{|l|}{ Total number of household members } \\
\hline$\leq 4$ members & $233(46.3 \%)$ & $117(46.1 \%)$ & $116(46.6 \%)$ \\
\hline 5 or more members & $270(53.7 \%)$ & $137(53.9 \%)$ & $133(53.4 \%)$ \\
\hline \multicolumn{4}{|l|}{ Monthly Income (in BDT) * } \\
\hline Interquartile Range (IQR) & $\mathrm{IQR}=7500$ & $\mathrm{IQR}=8000$ & $\mathrm{IQR}=8000$ \\
\hline$\leq 7500$ ( $\leq 95$ USD) & $153(30.2 \%)$ & $62(24.3 \%)$ & $91(36.1 \%)$ \\
\hline 7501 to 10000 (95 to 127 USD) & $117(23.1 \%)$ & $70(27.5 \%)$ & $47(18.7 \%)$ \\
\hline 10001 to 15000 (127 to 191 USD) & $113(22.3 \%)$ & $58(22.7 \%)$ & $55(21.8 \%)$ \\
\hline Above 15000 (above 191 USD) & $120(23.7 \%)$ & $64(25.1 \%)$ & $56(22.2 \%)$ \\
\hline
\end{tabular}

*4 non-responses

number of sticks smoked was $13.2 \pm 8.3$ per day. About $8.3 \%$ smoked locally made products such as bidis and hookahs. A small proportion (1.1\%) smoked a combination of two or more products. Majority (86.9\%) of the SLT users consumed jarda (a form of chewing tobacco, usually taken with betel quid), while 9.2\% consumed sada pata (dried plain tobacco leaves) and another 6.8\% used $g u l$ (powdered tobacco, often used as tooth powder for cleaning teeth). Overall $6.8 \%$ consumed a combination of two products and $0.97 \%$ used all three types.

The exposure status of the non-smokers to secondhand smoking (SHS) at their homes and workplaces have been depicted in Fig. 1. About 43\% reported exposure to tobacco smoke, while the rest mentioned that they were not exposed to any form of SHS due to tobacco consumption. Of those exposed, majority (32\%) were exposed to SHS at their homes only, while only $4 \%$ were exposed to SHS only at their place of work. About
7\% experienced SHS exposure both at their homes and workplaces.

The associations between the various types of tobacco consumption and the socio-demographic characteristics were determined by binary logistic regression, the results of which are presented in Table 3, in terms of unadjusted and adjusted odds ratio. The elderly respondents, aged between 55-64 years were twice more likely to smoke (OR: 2.34, 95\% CI: 1.21-4.49) than those who were 25-34 years old. The results further revealed that the manual workers were more than eight times (OR: 8.80, 95\% CI: $5.48-14.14)$ more likely to smoke than non-manual workers. For smokeless tobacco, those belonging to the $45-54$ years age group (OR: 2.15 , 95\% CI: 1.24-3.74) were twice more likely to consume SLT than the younger age group of 25-34 years. Also, those who had no schooling history (OR: 2.95, 95\% CI: 1.66-5.25) were almost three times likely to use smokeless tobacco 
Table 2 Prevalence of type of tobacco use among the adults by selected demographic characteristics

\begin{tabular}{|c|c|c|c|}
\hline Variables & Tobacco Smoking \% (95\% Cl) & $\begin{array}{l}\text { Smokeless Tobacco } \\
\text { Consumption } \\
\%(95 \% \text { Cl) }\end{array}$ & $\begin{array}{l}\text { Dual Use of Tobacco } \\
\%(95 \% \mathrm{Cl})\end{array}$ \\
\hline \multicolumn{4}{|l|}{ Sex } \\
\hline Male & $70.6(65.10-76.08)$ & $32.6(27.06-38.43)$ & $23.5(18.82-29.01)$ \\
\hline Female & $0.4(0.00-1.19)$ & $48.8(42.47-54.76)$ & $0.4(0.00-1.19)$ \\
\hline \multicolumn{4}{|l|}{ Age Categories (in years) } \\
\hline $25-34$ & $34.5(28.76-40.27)$ & $31.4(25.22-37.17)$ & $12.0(7.96-15.93)$ \\
\hline $35-44$ & $34.1(26.09-42.03)$ & $47.8(39.13-56.52)$ & $10.1(5.07-15.22)$ \\
\hline $45-54$ & $30.8(20.51-41.03)$ & $51.3(39.74-61.54)$ & $12.8(5.13-20.51)$ \\
\hline $55-64$ & $49.2(36.92-61.54)$ & $44.6(32.31-55.38)$ & $15.4(7.69-24.62)$ \\
\hline \multicolumn{4}{|l|}{ Highest Level of Education } \\
\hline No Formal Education & $30.7(25.30-36.40)$ & $49.0(42.92-55.16)$ & $10.7(6.91-14.56)$ \\
\hline Below Primary Level & $50.0(39.53-60.47)$ & $44.2(33.72-54.65)$ & $19.8(11.63-27.91)$ \\
\hline Primary Education completed & $35.5(24.19-48.39)$ & $30.7(19.35-41.94)$ & $11.3(3.23-19.35)$ \\
\hline Secondary Education and above & $36.7(27.55-46.94)$ & $21.4(13.27-30.61)$ & $9.2(4.08-15.31)$ \\
\hline \multicolumn{4}{|l|}{ Occupation } \\
\hline Non-manual & $22.3(17.90-27.10)$ & $40.7(35.80-45.90)$ & $6.5(4.20-9.30)$ \\
\hline Manual & $66.7(58.80-74.30)$ & $40.5(32.50-48.60)$ & $24.8(17.80-31.90)$ \\
\hline \multicolumn{4}{|l|}{ Monthly Income* } \\
\hline Less than/equal to 7500 ( $\leq 95$ USD) & $27.5(20.26-33.99)$ & $47.1(39.22-55.54)$ & $9.8(5.23-15.03)$ \\
\hline 7501 to 10000 (95 to 127 USD) & $44.4(35.90-53.85)$ & $42.7(34.19-52.14)$ & $14.5(8.55-21.37)$ \\
\hline 10001 to 15000 (127 to 191 USD) & $38.1(29.20-46.90)$ & $34.5(26.55-44.25)$ & $11.5(6.19-17.70)$ \\
\hline Above 15000 (above 191 USD) & $36.7(28.35-45.83)$ & $35.8(27.50-44.17)$ & $13.3(7.50-19.17)$ \\
\hline
\end{tabular}

than who had higher education (secondary or above). Those who were employed as manual workers were five times more likely to indulge in dual use of tobacco (OR: 5.17, 95\% CI: 2.82-9.48) than non-manual workers.

\section{Discussion}

The study describes the current status of tobacco use among the adults residing in three urban slums of
Dhaka along with associated socio-demographic correlates. Results show that the current tobacco use (both smoked and smokeless forms) among the slum population was higher than the comparable overall tobacco use figures in the national surveys, namely the Global Adult Tobacco Survey (GATS) [6] and the Bangladesh NCD Risk Factor Survey [7]. The overall tobacco consumption (64\%) was found to be higher compared to

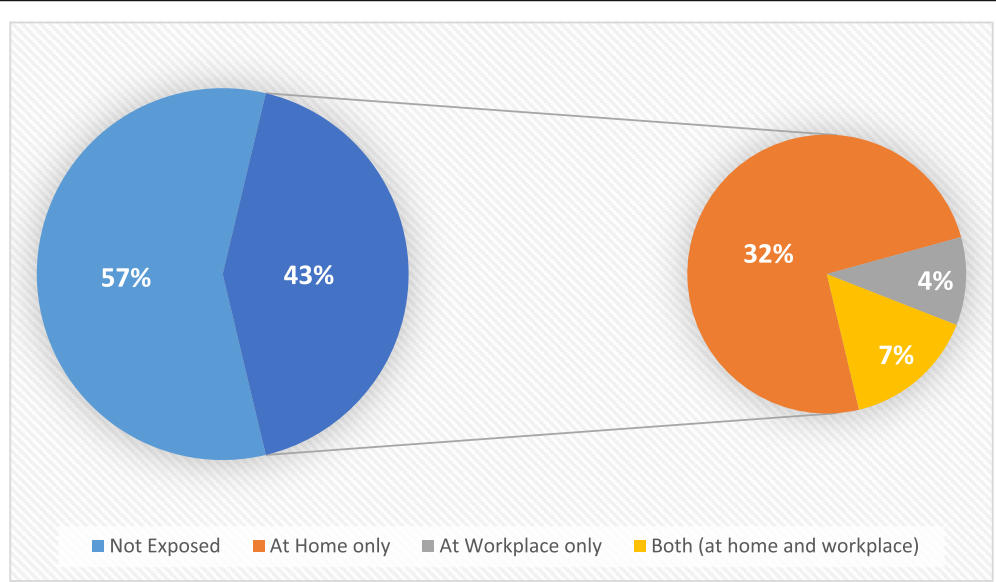

Fig. 1 Exposure to second-hand smoking among non-smokers 
Table 3 Logistic regression for the type of tobacco use among the adults residing in urban slums

\begin{tabular}{|c|c|c|c|c|c|c|}
\hline \multirow[t]{2}{*}{ Socio-demographic variables } & \multicolumn{2}{|l|}{ Smoking } & \multicolumn{2}{|l|}{ Smokeless Tobacco } & \multicolumn{2}{|l|}{ Dual Use } \\
\hline & Unadjusted & Adjusted\# & Unadjusted & Adjusted\# & Unadjusted & Adjusted\# \\
\hline & OR $(95 \% \mathrm{Cl})$ & OR $(95 \% \mathrm{Cl})$ & OR $(95 \% \mathrm{Cl})$ & OR $(95 \% \mathrm{Cl})$ & OR $(95 \% \mathrm{Cl})$ & OR $(95 \% \mathrm{Cl})$ \\
\hline \multicolumn{7}{|l|}{ Age Group } \\
\hline $25-34$ & Ref & Ref & Ref & Ref & Ref & Ref \\
\hline $35-44$ & $0.98(0.63-1.53)$ & $0.83(0.49-1.42)$ & $2.00(1.29-3.10)^{* *}$ & $1.68(1.06-2.67)^{* *}$ & $0.83(0.42-1.65)$ & $0.65(0.31-1.34)$ \\
\hline $45-54$ & $0.84(0.48-1.47)$ & $0.81(0.42-1.53)$ & $2.30(1.36-3.89)^{* *}$ & $2.15(1.24-3.74)^{* *}$ & $1.08(0.50-2.36)$ & $0.99(0.43-2.27)$ \\
\hline $55-64$ & $1.84(1.05-3.22)^{* *}$ & $2.34(1.21-4.49)^{* *}$ & $1.76(1.00-3.09)$ & $1.53(0.85-2.76)$ & $1.34(0.61-2.94)$ & $1.26(0.54-2.92)$ \\
\hline \multicolumn{7}{|l|}{ Education } \\
\hline No schooling & $0.76(0.47-1.24)$ & $0.49(0.27-0.89)$ & $3.53(2.06-6.06)^{* *}$ & $2.95(1.66-5.25)^{* *}$ & $1.19(0.54-2.62)$ & $0.98(0.41-2.34)$ \\
\hline Less than Primary & $1.72(0.96-3.10)^{*}$ & $0.98(0.49-1.94)$ & $2.90(1.53-5.52)^{* *}$ & $2.84(1.45-5.57)^{* *}$ & $2.44(1.02-5.80)^{* *}$ & $1.66(0.65-4.25)$ \\
\hline Primary completed & $0.95(0.49-1.84)$ & $0.77(0.36-1.63)$ & $1.62(0.79-3.34)$ & $1.46(0.69-3.09)$ & $1.26(0.44-3.57)$ & $1.11(0.37-3.32)$ \\
\hline Secondary and above & Ref & Ref & Ref & Ref & Ref & Ref \\
\hline \multicolumn{7}{|l|}{ Occupation } \\
\hline Manual & $6.96(4.58-10.59)^{* *}$ & $8.80(5.48-14.14)^{* *}$ & $0.99(0.68-1.46)$ & $0.79(0.52-1.20)$ & $4.76(2.72-8.32)^{* *}$ & $5.17(2.82-9.48)^{* *}$ \\
\hline Non-manual & Ref & Ref & Ref & Ref & Ref & Ref \\
\hline \multicolumn{7}{|l|}{ Income } \\
\hline Less than 7500 ( $\leq 95$ USD) & $0.65(0.39-1.09)$ & $0.48(0.26-0.88)$ & $1.59(0.98-2.60)^{*}$ & $1.32(0.78-2.24)$ & $0.71(0.33-1.49)$ & $0.53(0.23-1.20)$ \\
\hline 7501-10000 (95 to 127 USD) & $1.38(0.82-2.33)$ & $0.92(0.51-1.68)$ & $1.34(0.79-2.25)$ & $1.28(0.73-2.24)$ & $1.10(0.53-2.31)$ & $0.71(0.32-1.60)$ \\
\hline 10001-15000 (127 to 191 USD) & $1.06(0.62-1.80)$ & $0.73(0.39-1.34)$ & $0.94(0.55-1.62)$ & $0.84(0.47-1.48)$ & $0.85(0.39-1.85)$ & $0.54(0.23-1.27)$ \\
\hline Above 15000 (above 191 USD) & Ref & Ref & Ref & Ref & Ref & Ref \\
\hline
\end{tabular}

\#: variables adjusted in the models: age, education, occupation, income; **: $5 \%$ significant, *: $10 \%$ significant

the overall tobacco use in most of the states in neighbouring India [22].

Use of smoked tobacco was more prevalent among the males, which is universally acknowledged [1]. Moreover, compared to the national survey statistics, the findings from the current study implicate that the prevalence of tobacco smoking may be higher in the male slum population. This is complemented by the results of the International Tobacco Control (ITC) Bangladesh Survey 2010, which reports a higher percentage of smokers amongst male slum dwellers as compared to their counter-parts in the rest of the urban population [15]. A previous study (using the results from Urban Health Survey 2006) compared the prevalence of smoking among the males living in slums versus those living in urban areas of Bangladesh and also found a higher prevalence $(59.8 \%)$ among the slum dwellers as compared to their non-slum counterparts $(46.4 \%)$ [23]. The present study reports a smoking prevalence of $70.6 \%$ among the adult males and thus indicates an increase in male smokers over the years. On the contrary, only $0.4 \%$ of the female respondents were found to smoke tobacco which is lower than the NCD risk factor survey report of $1.3 \%$ female smokers [7]. Majority of the smokers (97.2\%) smoked on a daily basis. While this is consistent with national surveys $[6,7]$, it is higher than the worldwide estimate of $80 \%$ [1].
Majority of the smokers (89\%) smoked manufactured cigarettes, which is similar to the figures reported among slum dwellers in the ITC survey [15]. However, this finding is quite different from the findings from several years ago, which reports that $53.3 \%$ consumed manufactured cigarettes [23]. This shows a gradual transition towards manufactured cigarettes over the years, most possibly due to greater availability and ease of access to manufactured cigarettes.

In case of smokeless tobacco (SLT), the consumption statistics were higher for both male and female slum dwellers as compared to the national survey reports [6, 7]. The national figures are already high compared to the statistics reported by other SEAR countries like India, Myanmar, Nepal, Sri Lanka and Thailand [24] and even higher rates of SLT consumption among the slum population, particularly the females, are quite an alarming finding. Palipudi et al. (2014) suggested that the reason for this type of trend in SLT consumption among women is possibly because Bangladeshi society is largely conservative and regards smoking as undesirable behavior, especially among females [25]. In contrast chewing SLT products is not viewed as objectionable and thereby the number of females who use SLT are higher [25].

Furthermore, dual use of tobacco (both smoked and SLT) was also higher among the slum dwelling males placing them at a much higher risk of developing NCDs. A study 
conducted among Bangladeshi men reveals the proportion of dual use of tobacco to be $14.2 \%$ [26], which is distinctively lower than the finding from this study. In addition, the manual workers were more likely to indulge in dual tobacco use than non-manual workers. This might be gender moderated and not due to the occupation, as most of the females indulged in non-manual works and majority of the males as manual workers. The gender variable was left out in the models because there was only one female smoker and thus comparisons with the males did not result in any meaningful finding.

Besides direct consumption of tobacco products, second-hand exposure to tobacco smoke can also predispose a person to a relatively higher risk of tobaccorelated illnesses, such as ischemic heart disease, stroke and chronic obstructive pulmonary disease, even though they may be non-smokers. Findings from a study show that SHS exposure increases a person's chances of acquiring any one of these diseases by $21 \%$ [27]. Our study reveals that exposure to second-hand smoking (SHS) at home was reported by $39 \%$ of the non-smoker respondents. This figure is more or less similar to the values reported in the national surveys $(36.3 \%$ in the NCD risk factor survey and $43 \%$ in the ITC survey) $[7,15]$.

Age and occupation were found to be significant correlates of tobacco consumption. Age has been identified as a significant correlate of smoking status in many studies $[22,28]$. In this study, manual workers were found to be more likely to smoke. This finding is resonated in another study conducted in Bangladesh which reports that people having stressful and laborious jobs were 2.65 times more likely to smoke than those employed in service or business [28]. In the case of smokeless tobacco, education was found to be significantly correlated. Results showed that consumption of SLT went down with higher educational status, which is a reciprocal finding in other developing countries [4].

\section{Limitations}

One of the major limitations of the study was that, there was a possibility of under-reporting of the status of tobacco consumption, since the data collected was selfreported. Information on sensitive topics may have resulted in concealing of correct information, particularly in case of females. Another limitation remains in the fact that the population may not be representative of all the slum population in Bangladesh.

\section{Conclusion}

The increasing problem of tobacco use among the urban slum population has become a major public health threat for Bangladesh. People from low socio-economic condition are more likely to use tobacco and are vulnerable to developing NCDs. Therefore, there is a critical need for developing effective intervention approaches to address the NCD risk factors, thereby preventing the development of NCDs and their consequences.

\section{Acknowledgement \\ This study was the part of the Summative Learning Project (SLP) of MPH program at James P. Grant School of Public Health, BRAC University. We thank Ms. Sadia Chowdhury for her support preparing ethics application. We also thank SLP group members Mr. Abhinav Bassi, Ms. Sarjana Ahmed, Mr. Shekhar Ranjan Saha, and Dr. Mahiul Bidat Chowdhury for their contribution during tools development and data collection.}

\section{Funding}

This study was conducted as part of the student Master of Public Health $(\mathrm{MPH})$ research project while undertaking MPH program at James P. Grant School of Public Health, BRAC University, Bangladesh. The main author received a nominal amount of fund from the James $P$ Grant School of Public Health, to facilitate the field data collection process. Other authors do not receive any funding associated with this study.

\section{Availability of data and materials}

Our study does not involve developing new software, or new database or any particular product using the collected data. Therefore, the provision of this information may not be applicable in our case. However if necessary, we will be happy to make our database (which has been developed in SPSS) available for any future scientific work.

\section{Authors' contributions}

NNK and LR contributed to designing the study, drafting the manuscript and finalization. TB and ANSK contributed in data extraction, synthesis and analyses. LR, TB and EH thoroughly reviewed the manuscript and contributed substantially with necessary revision. NNK and LR finally reviewed the manuscript and prepared for submission. All authors approved the final version.

\section{Authors' disclosure}

The authors declare that they have no competing interests.

\section{Consent for publication}

This manuscript involved collecting individual level information collected using survey questionnaire. This does not contain any images of the individuals, biomedical data, or any information that will identify the individual participant. During the data collection process, in particular while obtaining the ethical consent, the participants were informed that their data may be used for the publication purpose, but will not be reflected or reported the personally identified information. Once the participant better understood about the study details and agreed upon, the interview was conducted.

\section{Ethics approval and consent to participate}

Ethics approval for conducting this study was obtained from the Ethical Review Committee of James P Grant School of Public Health, BRAC University, Bangladesh.

Due to the contextual setting where most of the participants were illiterate and the sensitive nature of asking for thumbprints or signatures, it was difficult to obtain written informed consents. Therefore, verbal informed consent was taken from the respondents before the interviews, by following a consent script. Prior to starting an interview, the consent script was read out clearly by the interviewer.

\section{Publisher's Note}

Springer Nature remains neutral with regard to jurisdictional claims in published maps and institutional affiliations.

Received: 22 July 2016 Accepted: 21 April 2017

Published online: 05 May 2017

\section{References}

1. World Health Organization: Global status report on noncommunicable diseases 2014. Geneva: World Health Organization; 2014. 
2. World Health Organization: Mortality attributable to tobacco: WHO Global Report. Geneva: World Health Organization; 2012.

3. Institute for Health Metrics and Evaluation. Global Burden of Disease (GBD). 2010. Retrieved October 3, 2015, from http://www.healthdata. org/gbd.

4. Eriksen M, Mackay J, Schluger NW, Islami F, Drope J: The Tobacco Atlas. Atlanta: The American Cancer Society; 2015.

5. World Health Organization. WHO Report on the Global Tobacco Epidemic 2008: The MPOWER package. Geneva, Switzerland: World Health Organization; 2008.

6. World Health Organization - Country Office for Bangladesh: Global Adult Tobacco Survey (GATS) Bangladesh Report. Dhaka: World Health Organization, Country Office for Bangladesh; 2009.

7. World Health Organization - Country Office for Bangladesh: Noncommunicable disease risk factor survey Bangladesh 2010. Dhaka: World Health Organization, Country Office for Bangladesh; 2011.

8. Alam DS, Jha P, Ramasundarahettige C, Streatfield PK, Niessen LW, Chowdhury MAH, Siddiquee AT, Ahmed S, Evans TG. Smoking-attributable mortality in Bangladesh: proportional mortality study. Bull World Health Organ. 2013;91:757-64

9. Wu F, Chen Y, Parvez F, Segers S, Argos M, Islam T, Ahmed A, Rakibuzzaman M, Hasan R, Sarwar G, Ahsan H: A Prospective Study of Tobacco Smoking and Mortality in Bangladesh. PLoS One. 2013;8(3).

10. World Health Organization: Tobacco: deadly in any form or disguise. Geneva: World Health Organization; 2006.

11. Efroymson D, Ahmed S, Townsend J, Alam SM, Dey AR, Saha R, Dhar B, Sujon Al, Ahmed KU, Rahman O. Hungry for tobacco: an analysis of the economic impact of tobacco consumption on the poor in Bangladesh. Tob Control. 2001:10:212-7.

12. National Institute of Population Research and Training (NIPORT), Measure Evaluation/UNC, International Center for Diarrhoeal Disease Research (ICDDR, B). Bangladesh Urban Health Survey 2013. Dhaka: NIPORT; 2014

13. Mahmood SAl, Ali S, Islam R. Shifting from infectious diseases to noncommunicable diseases: A double burden of diseases in Bangladesh. J Public Heal Epidemiol. 2013:5(November):424-34.

14. Hancock C, Kingo L, Raynaud O. The private sector, international development and NCDs. Glob Health. 2011;7:23.

15. The International Tobacco Control Policy Evaluation Project. ITC Bangladesh National Report. Waterloo, Ontario, Canada: University of Waterloo. Bangladesh: University of Dhaka; 2010.

16. Acharyya T, Kaur P, Murhekar MV. Prevalence of behavioral risk factors, overweight and hypertension in the urban slums of North 24 Parganas District, West Bengal, India, 2010. Indian J Public Health. 2014:58:195-8.

17. Chockalingam K, Vedhachalam C, Rangasamy S, Sekar G, Adinarayanan S, Swaminathan S, Menon PA: Prevalence of Tobacco Use in Urban, Semi Urban and Rural Areas in and around Chennai City, India. PLoS One. 2013;8(10)

18. World Health Organization: WHO STEPS Surveillance Part 2: Planning and Set Up Overview; Section 2: Preparing the Sample. WHO STEPS Surveill Man 2008. Geneva: World Health Organization; 2008.

19. World Health Organization: The WHO STEPwise approach to noncommunicable disease risk factor surveillance (STEPS). Geneva: World Health Organization; 2011.

20. World Health Organization: Noncommunicable Diseases Global Monitoring Framework: Indicator Definitions and Specifications. Geneva: World Health Organization; 2014

21. World Health Organization: Conducting the Survey, Data Entry, Data Analysis and Reporting and Disseminating Results Overview. WHO STEPS Surveill Man 2008. Geneva: World Health Organization; 2008.

22. Singh A, Ladusingh L. Prevalence and determinants of tobacco use in India: Evidence from recent global adult tobacco survey data. PLoS One. 2014;9:1-18.

23. Khan $\mathrm{MMH}$, Khan A, Kraemer A, Mori M. Prevalence and correlates of smoking among urban adult men in Bangladesh: slum versus non-slum comparison. BMC Public Health. 2009:9:149.

24. Thakur JS, Garg R, Narain JP, Menabde N. Tobacco use: a major risk factor for non communicable diseases in South-East Asia region. Indian J Public Health. 2011;55:155-60.

25. Palipudi K, Rizwan SA, Sinha DN, Andes LJ, Amarchand R, Krishnan A Asma S. Prevalence and sociodemographic determinants of tobacco use in four countries of the World Health Organization: South-East Asia region: findings from the Global Adult Tobacco Survey. Indian J Cancer. 2014;51 Suppl 1:S24-32

26. Zaman M, Bhuiyan M, Fernando T, Huq S, Rahman M, Sinha D. Dual use of tobacco among Bangladeshi men. Indian J Cancer. 2014;51:46.

27. World Health Organization: Impact of Tobacco-related IIInesses in Bangladesh. New Delhi: World Health Organization Regional Office for South-East Asia; 2007.

28. Sultana P, Akter S, Rahman MM, Alam MS: Prevalence and Predictors of Current Tobacco Smoking in Bangladesh. J Biostat Biometric App. 2015;1:1-8.

\section{Submit your next manuscript to BioMed Central and we will help you at every step:}

- We accept pre-submission inquiries

- Our selector tool helps you to find the most relevant journal

- We provide round the clock customer support

- Convenient online submission

- Thorough peer review

- Inclusion in PubMed and all major indexing services

- Maximum visibility for your research

Submit your manuscript at www.biomedcentral.com/submit 